\title{
Integrating Geography Skills in the Middle Grades: Instructional Change in South Carolina, USA
}

\author{
Michael MEWBORNE4 \\ University of South Carolina, Columbia, USA
}

\author{
Jerry T, MITCHELL2 \\ University of South Carolina, Columbia, USA
}

1 Corresponding author: Mr. University of South Carolina, Department of Geography, Columbia, USA. mewbornj [at] mailbox.sc.edu.
ORCID: 0000-0003-1643-2513
2 Prof. Dr. University of South Carolina, Department of Geography, Columbia, USA. mitchell [at] sc.edu. ORCID: 0000-0002-0654-4418

\begin{abstract}
In 2019, the State of South Carolina (USA) adopted new social studies standards with an emphasis on disciplinary skills in addition to content throughout the social studies areas of history, geography, civics, and economics. These skills were introduced for all grades, kindergarten through grade 12. Geography courses were added in grades 3 and 7. The standards specify and deconstruct six geography skills to be taught in these classrooms. These skills include Mapping; Models and Representations; Gather Evidence and Communicate Findings; Conditions, Connections, and Regions; Scale; and Distribution and Pattern. Social studies coordinators at the school district level were interviewed on the successes and obstacles teachers are experiencing, and on what future actions were being considered to address these skills in teaching.
\end{abstract}

\section{Keywords}

Geography Skills, Academic Standards, Middle Level Students 
"The goal of teaching geography is to equip students with the knowledge, skills, and perspectives to 'do' geography. Reaching this goal requires that students learn how to use geographic thinking and information to make well-reasoned decisions and to solve personal and community problems. Many valuable applications of K-12 geography education lie beyond the classroom walls. Geographic education enables students to use geographic perspectives, knowledge, and skills to engage in ethical action with regard to self, other people, other species, and Earth's diverse cultures and natural environments. Geography connects students to world events, problems, and decisions throughout their lives." (Heffron and Downs, 2012).

Twice in the preceding quote from the National Geography Standards (USA) Geography for Life - one reads not only about learning the content of this world, but also about using skills to 'do' geography. More broadly within the social studies civics, economics, history, and geography - there has been greater emphasis on inquiry or simply put the ability for students to "develop the capacity to know, analyze, explain, and argue about interdisciplinary challenges in our social world." (NCSS, 2013). Other disciplines have applied this skills focus. For example, math educators have "students learn the tools, mind-set, and habits of thinking mathematically so that they can then apply those skills to problems" (Lesh, 2017). This view of the social studies, and geography in particular, requires moving away from a descriptive education toward one that emphasizes questioning, gathering information, challenging sources, and having students take action to create for themselves a better life.

In South Carolina (USA), an impetus toward producing educational classroom standards for social studies that focused more on skills was the adoption of the Profile of the South Carolina Graduate in 2015 (Figure 1). Adopted by the State Board of Education at the behest of the business community and several education organizations, the profile focused on producing school graduates that had worldclass knowledge (via rigorous academic standards), life and career characteristics (work ethic, interpersonal skills), and world-class skills (knowing how to learn, among others). Several of these enumerated skills are present in good geography instruction: critical thinking, problem solving, using technology, and having a global perspective. The profile, too, possessed only one graphic element: a globe. The profile was used successfully to argue for not only more geography instruction, but the teaching of geography via a set of content standards that included a set of skills so that students could participate in authentic learning. In other words, students would learn about the world in a meaningful and exploratory manner that would prepare them to be successful in careers, college, and as citizens. 


\section{PROFILE OF THE South Carolina Graduate}

\section{WORLD-CLASS \\ KNOWLEDGE}

Rigorous standards in language arts and math for career and college

readiness

Multiple languages, science, technology,

engineering, mathematics (STEM), arts and

social sciences
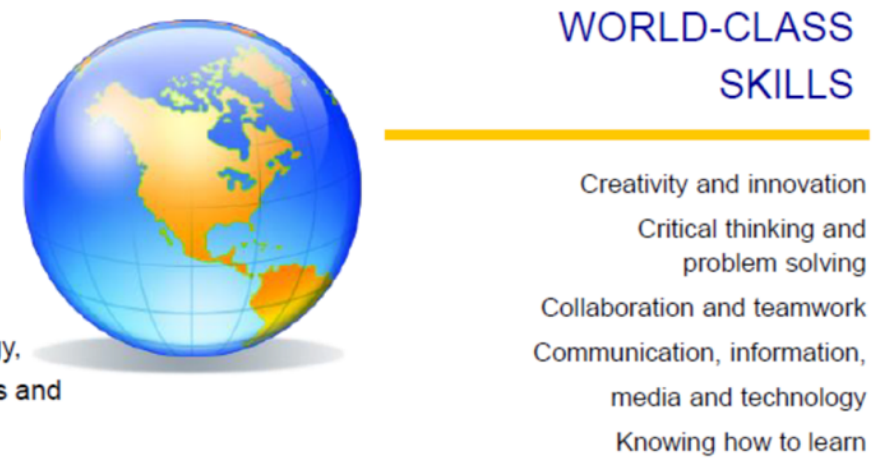

Integrity $\cdot$ Self-direction $\cdot$ Global perspective $\cdot$ Perseverance $\cdot$ Work ethic $\cdot$ Interpersonal skills

Figure 1. Profile of the South Carolina Graduate

The new standards and skills writing process was a multi-year project involving a national review panel, parent, business leader, teacher, and administrator reviewers, and a writing team that assimilated all revision suggestions into a new document that was adopted in 2019 (SCDE, 2019). Implementation began in 2019 and 2020 as decided by individual school districts. This process modeled a general strategy from the initial development of the original USA national geography standards where consensus building on the standards was succeeded by professional development to maximize implementation (de Souza and Monroe, 1994). This paper follows the South Carolina "roll out" by interviewing social studies coordinators and teachers about their experiences in enacting the new skills-based geography course of study and represents a preliminary look at their receptiveness and success.

\section{Standards and Skills}

\section{Academic Standards-Geography Internationally}

Developing standards and curricula in geography is a familiar action in many countries. These two terms - standards, curricula - have different meanings from one country to another but they are often used interchangeably. In some cases, standards refer to an outline of the content and skills to be taught while curricula refer to the specific lessons and activities undertaken to meet the standards. Here we refer to the primary sources that direct geography education in a country or subset of the same. Standards have been implemented for a number of reasons to include having a common base for promoting national identity and usefulness for conducting assessments. 
In Australia, the development of a national geography curriculum faced many of the same issues we describe in this paper. These issues included the roles of different stakeholder groups in defining geography, how to balance physical and human geography, and - importantly for our work here - how to integrate technical geography skills (e.g., mapmaking) with interpretive and analytical skills (e.g., contestation, appropriateness of data). The curriculum changes overall have been generally viewed as favorable by at least one author (Maude, 2014).

Positive stories with geography standards are not universal. National curriculum changes in South Korea, a very top-down, centralized education environment, were the source of negative outcomes for geography education argue Lee and Butt (2014). These included a decline in the number of students studying geography and a diminished content focusing on issues selectively deemed important by the state. Elsewhere, English national curriculum (standards) has been critiqued for "controlling" what and how teachers teach (Mitchell, 2016).

Recent changes to the Czech national geography curriculum present other areas of consideration (Spurná, Knecht, and Svobodová, 2020). Among these are consistency in progression, congruency between stated objectives and outcome measures, and maintaining a balance of geographical perspectives (see Catling, 2004).

\section{Academic Standards - Geography in the United States}

The academic standards movement in the United States stems from the 1980s, and while there are national standards in geography and other disciplines, these standards are not national in the sense that they are binding. These standards are advisory only, and the individual fifty states create (or do not) their own sets of standards. National Standards such as Geography for Life $(1994,2012)$ can and are used by states to craft their own standards, but the variation in these standards for geography vary considerably from state to state in terms of content, the grades taught, and the skills emphasized. Following the adoption of the first set of National Geography Standards in 1994, Bednarz (2003) researched their implementation to find incongruence among nature (form) and intent (function) among the factors that limited their influence in instruction. These themes - along with authority, power, prescriptiveness, and consistency - are used to explain challenges and opportunities observed in the South Carolina case.

\section{Academic Standards-Geography in South Carolina}

In South Carolina, academic standards exist for math, language arts, and science, among other disciplinary areas. Geography exists in the social studies standards which also include civics, economics, and history. New in the 2019 social studies standards were stand-alone geography instruction in grades 3 and 7. Geography previously existed in grade 9 and was updated in this set of standards. Previous standards versions were heavy on social studies content with little emphasis on skills, or how to 'do' social studies. A common critique when assessing the older 
standards prior to the current revision was the lack of skills integration (SCEOC, 2016). This was true for other subjects such as history where a newfound emphasis has been placed on comparison, contextualization, and periodization among other historic thinking skills that were to be paired with content instruction.

Standards writing with an emphasis on geography skills requires identifying the proficiencies expected to 'do' geography. Geography for Life (2012) - the National Geography Standards - are not helpful in this regard. Within that document, geography skills are identified as 1) Asking Geographic Questions, 2) Acquiring Geographic Information, 3) Organizing Geographic Information, 4) Analyzing Geographic Information, and 5) Answering Geographic Questions. The point about skills in these standards was to focus on "what the student is doing as opposed to what the student may know or understand." (Heffron, 2012). The problem inherent here is that there is no geography - conceptual or otherwise - in this list of skills. One can substitute the term geographic with biology and an educator is no closer to understanding what it means to 'do' geography. As a result, the new South Carolina standards were written with a set of skills that can be described in two parts: the actions behind doing geography and the language or concepts employed for geographic analysis and understanding.

\section{Geography Skills in South Carolina}

For a variety of reasons including the practical, such as the amount of space available in a document, the South Carolina Department of Education limited the number of skills taught to six. A team of standards writers that included university geographers and practicing schoolteachers settled on the following for emphasis in geography teaching. The first three encompass 'doing' while the latter three skills are conceptual and link to some of the spatial thinking skills identified by Gersmehl (2014).

Mapping, Students will "identify, use, interpret, and construct maps." The skill focuses on the student's ability to identify and describe the properties and functions of maps, use paper and digital map technologies, interpret maps for problemsolving, and construct maps. In an example that connects this skill to two others identified below, students may use mapping to identify potential resources (e.g., iron, coal) in Antarctica, discuss conditions and connections that make extraction impractical (e.g., resources under ice and far-flung from markets), and gather evidence on climate change that may render future extraction possible by nearby actors in similar locations (e.g., Russia in the Arctic Circle).

Models and representations. Students will "identify, use, interpret, and construct geographic models and other visual representations." This skill focuses on describing alternative methods of displaying geospatial data and using models to simplify the world for explanation. Use of the Demographic Transition Model, Central Place Theory, photographs, bar graphs, or tables to describe and understand the world outside of maps is a key aim, here. 
Gather evidence and communicate findings. Students will "identify, use, and interpret different forms of evidence, including primary and secondary sources." "Learning to find and evaluate information is assuming even more importance as a skill in the twenty-first century" (Chapin, 2007), if only because of the sheer amount of information available to students (Wineburg, 2018). Here students collect geospatial data, evaluate data accuracy, quality, perspective, and value, and synthesize their findings in written, visual, or other appropriate forms. For example, a student may read the diary of a mariner, plot their journey at sea, and associate the ocean and wind currents aiding or hindering passage.

Conditions, connections, and regions. Students will "identify and compare the development of conditions, connections, and regions." The aim of this skill is to investigate the physical and human conditions of places and understand how they are connected to other places. Climate analogs - having the student look at the conditions in Charleston, South Carolina to see how those conditions are very similar to those in Shanghai, China is an example of this skill in action.

Scale, Students will "identify spatial hierarchies." Here the focus in not on scale in the map sense (Earth space versus map space), but rather the hierarchies that exist on Earth in both physical and human geographies. Water can be hierarchical (creek to stream to river to bay to ocean); so, too, are political units (city to county to state to country). The goal is for students to see how actions at one scale may vary at another. For example, at the local scale automobile exhaust is a respiratory irritant but at the global level can contribute to climate change.

Distribution and Pattern. The sixth skill has students "identify spatial distributions, patterns, and associations." The world's deserts are at similar latitudes; many cities in the eastern United States follow the Fall Line, a geologic boundary; earthquakes are associated with the Pacific Ring of Fire; and so on. Students use this skill first to identify and then with guidance and evidence gathering, explain the patterns.

In the hands on a skilled teacher, few if any of these skills will be taught in isolation. Evidence gathering may produce a table of data that is then mapped; the map may have patterns needing explanation, for which the student investigates local conditions to do so. The goal, then, is to have students armed with skills (or the ability to reason geographically) that can be applied to a variety of places and contexts.

The purpose of this paper is to assess the reception of these new skills in the classroom. While the geography skills appear nearly the same in grade 3, 7, and 9 classrooms, here we focus on the responses of educators focused on introducing the skills to teachers and students in grade 7. In South Carolina, schools are organized and managed as a group in a unit called a school district. Many of these districts employ disciplinary support personnel (coordinators) to help teachers with their instruction. In this paper we share the results of our interviews with six 
coordinators and thirteen teachers, specifically focusing on how the geography skills integration is faring in instruction.

\section{Method}

The South Carolina Geographic Alliance (SCGA) is an organization that provides professional development and curriculum support to South Carolina teachers. Members of the SCGA leadership team were among the primary writers of the new social studies standards and geography skills. Several workshops have been conducted by the SCGA to promote understanding of the new standards and pedagogical strategies for their implementation. As a result, the SCGA has a unique insight into the successes teachers are having in implementing the geography skills in their instruction.

To assess progress and identify opportunities to strengthen instruction, the SCGA contacted sixteen coordinators in fifteen South Carolina school districts. Each was identified for recently participating in professional development where the geography skills were directly addressed. The districts represent different areas of the state and a wide variety of constituencies (e.g., rural, urban, regional). Six coordinators responded to our outreach and their responses were gathered in an online form. Additional teacher voices are heard as one coordinator shared the short survey with some teachers.

Each coordinator was presented with the following three prompts:

1. Describe the successes that you and your teachers are having with the 2019 geography skills in the new social studies standards for grades 3,7 , and 9 . What is responsible for those successes?

2. Describe the obstacles that you and your teachers are having with the 2019 geography skills in the new social studies standards for grades 3,7 , and 9 . What are the drivers behind those obstacles?

3. What plans does your district have moving forward in sharing successes and/or overcoming obstacles for student success?

For the purposes of this article, we refer to the responses to question 1 as "successes," question 2 as "obstacles," and question 3 as "further action."

\section{Results and Discussion}

\section{Coordinators}

A social studies coordinator is charged with providing leadership and instructional support to ensure effective classroom instruction. These professionals keep up to date in new developments in curriculum, instruction, and assessment, sharing with and coaching teachers in their districts. Some large school districts may have elementary and secondary coordinators. As such, they have their eyes on teachers as they introduce the new geography skills into their classrooms and are a useful group to interview. The efforts of six coordinators are described in this paper. 
Successes in teaching with skills. As few teachers at this level have a substantive background in geography themselves in their own education programs (Mitchell 2018), coordinators reported the formation of networks among districts and teacher groups at individual schools. These networks served to share resources, provide explanation of the skills in action, and suggest content that served to make using the skills real for students. One coordinator said that teachers had created their own online forum in their school's learning management system dedicated to requesting and sharing resources. This action would be similar to the collaborative sharing ("banding together") described by Mitchell for a set of teachers in English schools (2016). Multiple districts highlighted teacher-led curriculum development teams that met over the summer to plan, create, and pool resources in advance.

Working together, the teacher teams taught each other how skills integration could enhance content learning, and how those skills were then transferrable to other topics. This teacher learning was enhanced by having the district coordinators reach out to the SCGA for professional development. The SCGA created and then demonstrated lessons in a series of workshops.

As an example, we describe one activity here. The grade 7 standards are organized by continental region. Teachers can choose a region by region teaching structure or teach topically across regions as the general standard (culture, vegetation, political geography, etc.) is maintained in each region. In one activity focused on South America ${ }^{1}$, students are faced with this guiding question: "How have migration patterns influenced the contemporary religious landscape in South America?" Students gather data on religious percentages by country (Figure 2), use a digital spreadsheet such as Google Sheets for mapping (Figure 3), and then interpret and explain Roman Catholic patterns on the continent.

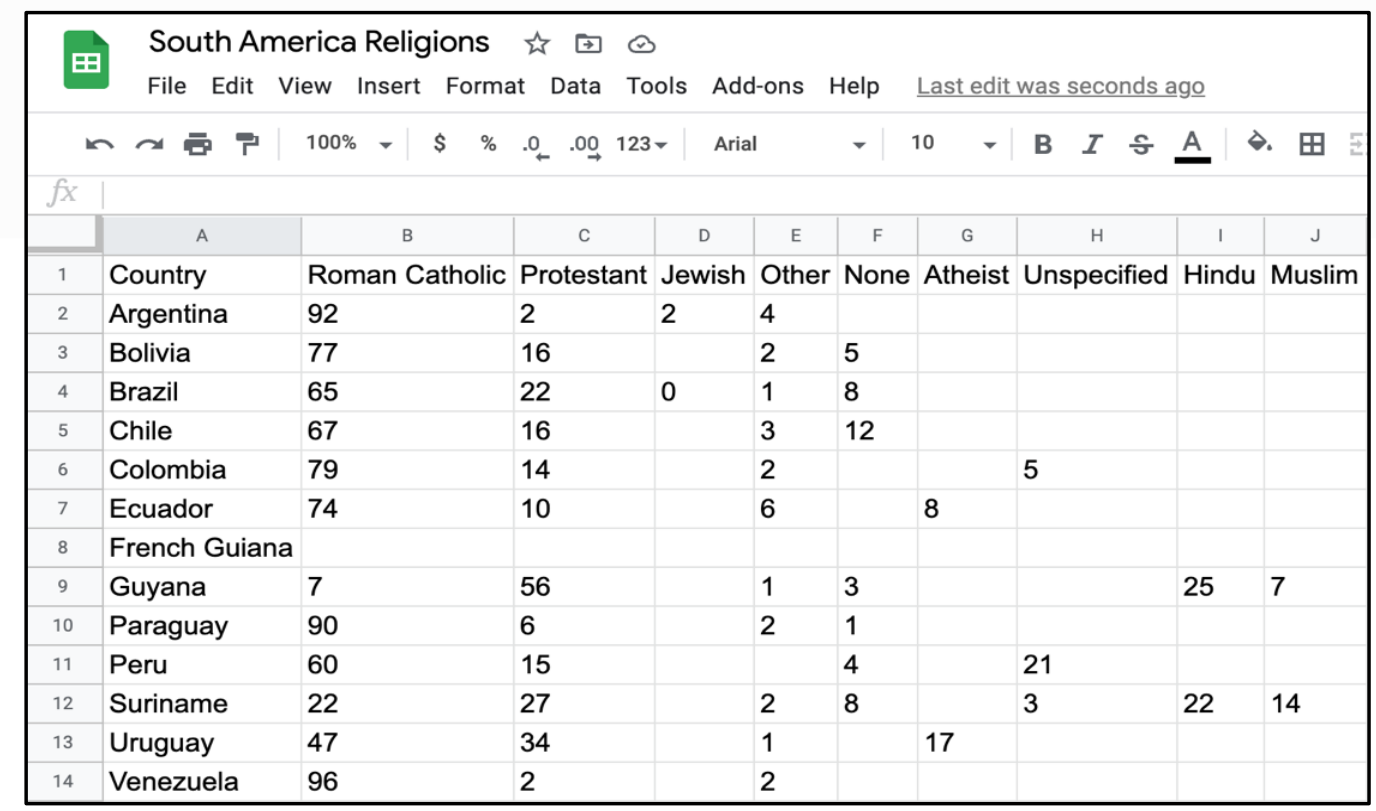

Figure 2. Student gathered religious data by South American country from the CIA World Factbook (2020). 


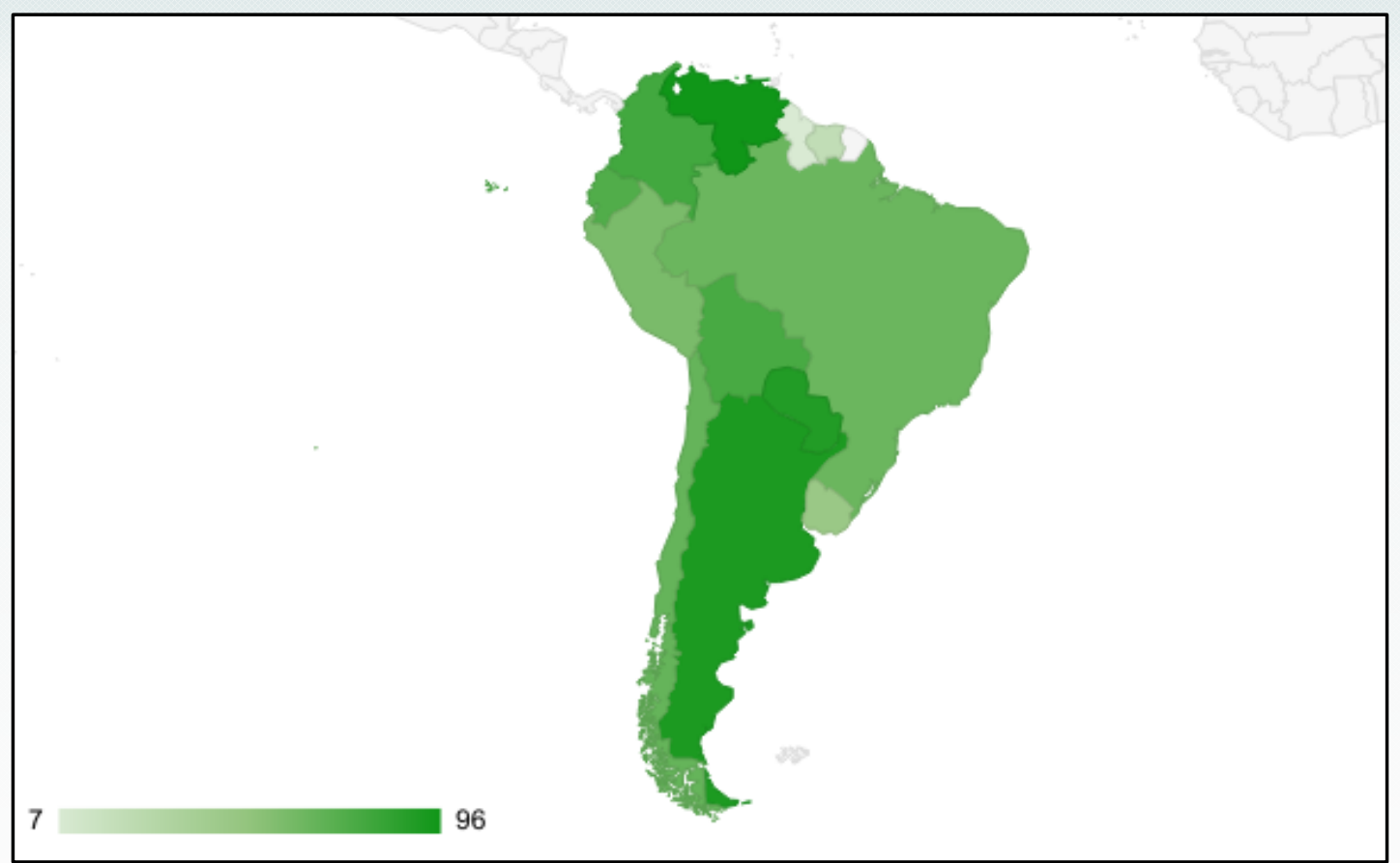

Figure 3. Sample student map of Roman Catholic religious patterns in South America

We do note, however, that only one skill - based on the coordinator feedback seems to be used regularly. This is mapping as shown here. Though unsurprising as mapping is the foremost skill associated with teaching geography, the coordinators report that some students are "labeling maps, but not drawing conclusions" about the information those maps convey. This presents two issues. First, teachers require additional assistance in using this one skill effectively, and second, it demonstrates that more professional learning is needed by teachers for them to feel comfortable enacting the other skills in their instruction.

Coordinators also shared that most classrooms lacked a geography textbook that could be used with instruction. Though not universally shared as a plus, some teachers were pleased as the absence of a single text drove teachers and students toward multiple resources rather than "just reading through" one source. The lack of a textbook facilitated the development of teacher-made resources that were then collected, organized, and filtered through the new networks to help their colleagues and their students. When faced with one source like a textbook, teachers are apt to revert to a content-focused as opposed to a skills-focused instructional strategy.

One important success is that the new focus on teaching geography skills with content led to the coordinators frequently identifying improved levels of student excitement about geography. One coordinator noted, "kids don't ask 'why do we have to learn this?' [anymore]" while another stated that "students are asking probing questions of their teachers and one another." Several coordinators noted that both teachers and students have "embraced the new standards" and are eager to learn more. 
Obstacles to teaching with skills. Three obstacles stand out, and the first is a counter to the previous responses about the lack of a single textbook. Given that so many teachers do not have a geography background of their own, coordinators reported a general lack of content knowledge that was still present, making it difficult for some teachers to focus on skills when they felt unprepared overall. This then brings the focus again to long-term, sustained professional development in geography as a necessary component in skills-based teaching framework.

A second obstacle is the lack of standard assessments for skills. Geography assessment can often be basic recall (e.g., what is the name of this place?) and as a result is part of the problem in poor geography teaching. Assessments need to be created that focus on the problem-solving skills that are developed by students. For example, students may be presented with a map that shows the location of three cities and several bodies of water; the task can be to identify the location most likely to flood. This task would assess the skills of mapping and conditions. The SCGA is creating assessment exemplars in concert with two local districts to address this issue.

A final impediment faced by teachers everywhere in 2020 and 2021 is the COVID19 pandemic. Coordinators note that these teachers are facing a new set of academic standards and implementing a skills-based instructional strategy in addition to a dynamic teaching environment that has them sometimes in a regular face to face classroom and then online in the same week. Understandably a move to skill-based instruction in geography will take time, and this has been further slowed by a public health crisis.

Further action for skills implementation in teaching, Continued collaboration was the most mentioned "further action" among coordinators. Multiple coordinators are communicating and collaborating frequently and intentionally with their counterparts from around the state. Supporting teacher leaders and cross-district collaboration among teachers in their district was a common plan. Teachers are being tasked with creating "problem-based inquiries for each unit" and identifying any "disconnects between standards and skills." Additional professional development with the SCGA is another planned strategy.

\section{Teachers}

Thirteen teachers provided additional information on the skills introduction process. We reached out to one teacher directly as she was our primary contact within their district; the other twelve teacher responses came to us through one of our district coordinators.

Successes and obstacles in teaching with skills. As noted by the coordinators, teachers most frequently mentioned excitement by students and themselves about the skills and content. Their students "enjoy" geography, and they link that enjoyment to the hands-on and practical nature of the course. Interweaving skills and making connections between geography, science, and mathematics were also 
identified as successes. Praise was also given to the content support provided by their school districts.

Two obstacles stand out among others less mentioned. These are geography preparation and textbook access. These obstacles match those offered by the coordinators and go hand in hand with each other. Without confidence in their geography knowledge, teachers are grasping for any resource and most commonly focus on textbooks, noting that "we need a book or some kind of resource for maps" and "I do not understand how it is possible to go into a new standard without a textbook." "Outdated maps in classrooms and no globes" further their complaint. On this point, teachers are less sanguine than the coordinators, especially when faced with the time constraints placed on them with new material and the global pandemic. This has had a direct impact on fulfilling the task of incorporating all geography skills into instruction. As teachers work to find, create, or integrate new materials and methods, some skills end up receiving more or less attention. As an issue identified by the coordinators, teachers also recognized this shortcoming early in the adoption process. Even in the district provided support this imbalance exists: "There were more activities that focused on mapping and not so much on the other skills, so I had to make some of my own." Teachers did not identify any further action, anticipating that their districts through their coordinators would provide that direction.

An additional struggle for some teachers is the disconnected nature of the geography skills and the geography standards. No standard specifically states that any one skill is used at a particular point. While it may be obvious to a practicing geographer that after creating a map of vegetation in Africa (skill: mapping), a teacher would work to explain the resulting output (skill: distribution and pattern) we find that some educators are not prepared to take this next step with their students. It is both a matter of professional development and the eventual identification and/or creation of resources that will take time that is needed to bridge this gap.

\section{Conclusion and Future Directions}

Teachers and coordinators report that while there is excitement about the new geography standards and an enjoyment of the new content and discipline-specific skills by students, obstacles such as a lack of confidence and capability in teaching geography and a lack of access to resources must be addressed. Plainly, change toward a skills-based curriculum occurred before the groundwork for teacher success could be laid. This speaks to the form/function argument made by Bednarz (2003) whereby teachers are ready to make changes to how they teach (form) but there is still a need to fundamentally change teachers' limited understanding of geography to teach the subject well as was the intent of the standards/skills developers (function). 
Though focused on GIS teacher training, the work by Höhnle et al. (2016) lays out a path for South Carolina educators and coordinators to move forward. Therein those authors identify duration, professional learning communities, institutional framework, and integration of diverse expertise as keys to success. Long-term support for teachers must be continued by coordinators and partnering with the SCGA ensures the integration of geographic expertise. The in-district and in-school networking allows teachers to reflect on teaching experiences together and should be encouraged. Greater emphasis can be placed on the institutional framework as not all school administrators have provided "buy-in" for the new skills-based approach to be successful (see authority and power per Bednarz, 2003). Often, a focus remains on time spent in reading and mathematics at the expense of social studies. Limiting teaching time for geography cannot enable the change expected.

Introducing the six geography skills in instruction has been unhurried, with one - mapping - far outpacing the others. Given the specific references to mapping, professional development opportunities can be created and implemented by the SCGA to build teacher confidence and student abilities by focusing on this skill further. Resources should be created to bring students from surface-level skills (e.g., using a legend to identify features), to more comprehensive skills (e.g., analyzing patterns). However, much more work is needed in teaching the teachers geography content and how to use the other skills before they feel confident in doing so with their students. It will be a multi-year project to build teacher proficiency and confidence and to create resources that are readily available and clearly aligned to the geography standards and skills. Many teachers are still hampered by content and skills that are to them hard to grasp (possibly a need for greater prescriptiveness? see Bednarz, 2003) and therefore limiting more successful implementation. District coordinators can aid this process be providing feedback and coaching, and by allowing teachers the ability to experience their own efficacy in teaching with the geography skills (Höhnle et al., 2016).

A first look at the new skills-based approach to teaching geography in South Carolina has identified an excitement and a reluctance at the same time. We are too early in the adoption process to make claims about change in student ability, though we are engaging in assessment development toward that goal. There is still much work to be done, but we do tentatively offer this appraisal: the promise of "doing" geography in South Carolina is slow going, but it is possible.

Note : 1 . Lesson examples are available at www.scgeo.org. 


\section{References}

Bednarz, S. (2003). Nine Years On: Examining Implementation of the National Geography Standards. Journal of Geography, 102(3): 99-109.

Catling, S. (2004). An understanding of geography: The perspectives of English primary trainee teachers. GeoJournal, 60(2): 149-158.

Chapin, J. (2007). A Practical Guide to Middle and Secondary Social Studies. $2^{\text {nd }}$ ed. New York: Pearson.

De Souza, A. \& Munroe, S. (1994). Implementation of Geography Standards: Potential Strategies and Initiatives. Journal of Geography, 93(1): 46-49.

Geography Education Standards Project. (1994). Geography for Life. Washington D. C.: National Council for Geographic Education.

Gersmehl, P. (2014). Teaching Geography. New York: Guilford.

Heffron, S. (2012). GFL2! The Updated Geography for Life: National Geography Standards, Second Edition. The Geography Teacher, 9(2), 43-48.

Heffron, S. \& Downs, R. (eds.). (2012). Geography for life: national geography standards. Washington, D. C.: National Council for Geographic Education.

Höhnle, S., Fögele, J., Rainer Mehren, R., \& Schubert, J. (2016). GIS Teacher Training: Empirically-Based Indicators of Effectiveness. Journal of Geography, 115(1), 12-23.

Lee, J. \& Butt, G. (2014). The reform of national geography standards in South Korea trends, challenges and responses. International Research in Geographical and Environmental Education, 23(1): 13-24.

Lesh, B. (2017). "Why Won't You Just Tell Us the Answer?" Teaching Historical Thinking Skills in Grades 7-12. Cheltenham, Victoria, Australia: Hawker Brownlow Education.

Maude, A. (2014). Developing a national geography curriculum for Australia. International Research in Geographical and Environmental Education, 23(1): 40-52.

Mitchell, D. (2016). Geography teachers and curriculum making in "changing times." International Research in Geographical and Environmental Education, 25(2): 121-133.

Mitchell, J. T. (2018). Pre-Service Teachers Learn to Teach Geography: A Suggested Course Model. Journal of Geography in Higher Education, 42(2), 238-260.

National Council for the Social Studies (NCSS). (2013). The College, Career, and Civic Life (C3) Framework for Social Studies State Standards: Guidance for Enhancing the Rigor of K12 Civics, Economics, Geography, and History. Silver Spring, Maryland: NCSS.

South Carolina Department of Education (SCDE). (2019). South Carolina Social Studies College- and Career-Ready Standards. Columbia, South Carolina: SCDE.

South Carolina Education Oversight Committee (SCEOC). (2016). SC Social Studies Academic Standards Cyclical Review Report. Columbia, South Carolina: SCEOC.

Spurná, M., Knecht, P. \& Svobodová, H. (2020). Perspectives on geography education in the Czech National Curriculum. International Research in Geographical and Environmental Education, DOI: 10.1080/10382046.2020.1789807.

Wineburg, S. (2018). Why Learn History (When It's Already on Your Phone). University of Chicago. 


\section{Biographical Statements}

Michael Mewborne is the Associate Director of the South Carolina Geographic Alliance at the University of South Carolina, Columbia, USA. He previously taught World Geography and Advanced Placement Human Geography at Chapin High School and River Bluff High School in South Carolina, USA.

Jerry T, Mitchell is Professor and Chair of the Department of Geography at the University of South Carolina, Columbia, USA. His research interests include geography education, environmental hazards, and Latin America. 